\title{
COMPARISON OF LOCAL ADMINISTRATION OF AMINOPHYLLINE VERSUS NORMAL SALINE ON TRANSURETERAL LITHOTRIPSY IN PATIENTS PRESENTING WITH ACUTE RENAL COLIC
}

\author{
Hasham Khana, Ghulam Mustafa ${ }^{b}$, Saqib Butt', Noor-Un-Nisa ${ }^{d}$, Ehsan-Ul-Haque ${ }^{e}$ \\ a'Senior Registrar, Department of Urology, Akbar Niazi Teaching Hospital, Islamabad. \\ ${ }^{b}$ Senior Registrar, Department of Urology, Islamabad Medical and Dental College, Islamabad. \\ 'Assistant Consultant, Department of Anesthesiology, Islamabad Medical and Dental College. \\ ${ }^{\mathrm{d} S}$ Senior Registrar, Department of Anesthesiology, Sheikh Zayad Hospital, Lahore. \\ e Medical Officer, Department of Urology, Federal Government Polyclinic Hospital, Islamabad.
}

\begin{abstract}
:
BACKGROUND \& OBJECTIVE: Acute renal colic is most common disease presented with agonizing pain worldwide. Our study aims to compare outcomes (mean operative time and frequency of complete stone removal) between local administrations of aminophylline versus saline on Transureteral lithotripsy (TUL) in patients presented with acute renal colic.

METHODOLOGY: Our study design was randomized clinical trial, conducted at department of Urology \& Kidney in Pakistan Institute of Medical Sciences, Islamabad. Study duration was 6 months (February 2017-July 2017). Ethical approval and consent forms were taken in our study. A sample size of 90 cases was calculated ( $1: 1$ randomization that is 45 patients in each group) using WHO calculator. Acute renal colic patients were selected through consecutive (non-probability) sampling. A random division of patients is done in two groups; Group-A underwent local administration of aminophylline and group-B patients were given placebo. SPSS version 24 was used for analysis purpose. Post stratification chi-square and t-test was utilized in analysis for comparisons. In our study, $\mathrm{p}$-value $\leq 0.05$ was found significant.

RESULTS: Total 90 cases were included in study. Mean age of patients was 47.56 18.1 SD. Mean operative time was found to be significantly lower in Group-A (aminophylline group) as compared to group-B (placebo group) $p=0.000$. Group-A patients showed significantly high stone removal frequency as compared to group-B (44.4\% vs $35.6 \%, p=0.03)$.

CONCLUSION: Aminophylline is an effective and safe drug in terms of lower operative time and complete stone removal among acute renal colic patients undergoing transureteral lithotripsy.

KEYWORDS: Acute renal colic, Aminophylline, Transureteral lithotripsy.
\end{abstract}

How to cite this:

doi: https://doi.org/10.37723/jumdc.v11i3.417

Khan H, Mustafa G, Butt S, Rehan G, Nisa UN, Haque EU. COMPARISON OF LOCAL ADMINISTRATION OF AMINOPHYLLINE VERSUS NORMAL SALINE ON TRANSURETERAL LITHOTRIPSY IN PATIENTS PRESENTING WITH ACUTE RENAL COLIC. jumdc. 2020;11(3):25-30.

doi: https://doi.org/10.37723/jumdc.v11i3.417

This is an Open Access article distributed under the terms of the Creative Commons Attribution License (http://creativecommons.org/licenses/by/4.0), which permits unrestricted use, distribution, and reproduction in any medium, provided the original work is properly cited. 


\section{INTRODUCTION:}

Acute renal colic is most common disease presented with agonizing pain worldwide ${ }^{[1]}$. Incidence of acute renal colic ranges from 5$15 \%$ depending upon geographical distribution ${ }^{[2]}$. Acute renal colic is more prevalent among males than females. Acute renal colic referred to severe pain as a result of urinary tract blockage with urinary stones. Acute renal colic is associated with radiation to groin, acute onset of flank pain, dysuria and serious hematuria ${ }^{[3]}$. Literature reported $50 \%$ recurrence rate in this diseases ${ }^{[4]}$. Acute renal colic is responsible for an annual cost of 6 billion dollars in United States. Global prevalence of acute renal colic based on stone belts varies in different regions (western hemisphere 5-15\%, eastern hemisphere $1-5 \%$, Afro-Asian belt including Pakistan 4-20\% $)^{[5]}$.

Literature reported several risk factors for stone formation including inadequate urinary volume, elevated urine level of uric acid, hypercalciuria, inadequate urinary citrate levels and infection stones ${ }^{[6]}$. Pathophysiology of acute renal colic referred to movement of stone from renal collecting system affecting genitourinary tract, reducing ureteral peristalsis rate, obstruction and hydonephrosis of ureter and enhancing urine back flow to kidney. Chronic renal pain is defined as pain lasting more than 3 months or longer. Chronic pain is caused by prolonged tissue injury with continuous activation of nociceptors. Diagnosis of acute renal colic is made by basic metabolic panel (investigation of dehydration, electrolyte balance, serum calcium complete blood count, renal function and acid base status). Helical/unenhanced computed tomography is gold standard for initial assessment, however, an abdominal $x$ ray (KUB) is effective in identification of $10-20 \%$ of renal stones and leads to understand obstruction, hydronephrosis and kidney functioning ${ }^{[7]}$. Transabdominal ultrasound is also a safe and non-invasive method for diagnosis of patients with kidney stones, loin pain and other urinary infections.

Evidence exist that aminophylline and theophylline are derived from xanthenes groups and are purely methylxanthines. Aminophylline is supposed to be different from theophylline in terms of structure. Literature reported that
Corresponding Author:

Dr Hasham Khan

Senior Registrar, Department of Urology,

Akbar Niazi Teaching Hospital, Islamabad.

I Email: HashamKhan86@yahoo.com

aminophylline is found to have short duration of action and less potent. Mechanism of action of aminophylline is based upon two processes. According to first process, aminophylline is a non-selective inhibitor (phosphodiesterase) associated with intracellularcyclic adenosine monophosphate enhancement, Protein kinase a activation, Tumor Necrosis Factor alpha inhibition, leukotriene synthesis and inflammation reduction. In second process, aminophylline is a (non-selective) antagonist of adenosine receptor. Aminnophylline is an effective drug in treatment of acute renal colic phase ${ }^{[8]}$. Barzegarnezhad et al. reported that aminophylline is associated with high success rate in renal colic patients with transureteral lithotripsy. Aminophylline leads to several benefits including decrease process duration, decrease stone migration towards kidney, reduce ureteral and catheter (double J) need ${ }^{[9]}$. Djaladat et al reported that aminophylline is an effective drug is pain relief and reduce narcotic usage. It is found as a safe and low cost drug with minimum side effects in renal colic management ${ }^{[10]}$. Acute renal colic is a common emerging issue in developing countries. Literature available on aminophylline efficacy in acute renal colic patients during transureteral lithotripsy is not enough to reach any conclusion in developing world. Present study aims to compare outcomes (mean operative time and frequency of complete stone removal) between local administrations of aminophylline versus saline on Transureteral lithotripsy (TUL) in patients presented with acute renal colic.

\section{METHODOLOGY:}

A randomized clinical trial was conducted at Urology \& Kidney transplantation department of Pakistan Institute of Medical Sciences, Islamabad. Study duration was 6 months (February 2017-July 2017). The study has been approved by the ethical review committee of Shaheed Zulfiqar Ali Bhutto Medical University (PIMS) Islamabad. Consent forms were signed 
by all participating patients. Sample size of 90 cases; 45 cases in each group is calculated with $90 \%$ power of test, $5 \%$ level of significance and taking expected percentage of complete stone removal i.e. $95 \%$ with aminophylline and $71.6 \%$ with normal saline in patients with acute renal colic ${ }^{[9]}$. Patients were selected with consecutive, (non-probability) sampling. Inclusion criteria was based upon both genders, age 16 to 75 years and patients presented with acute renal colic [defined as lower abdominal pain (VAS $>4$ ) with presence of renal stone $>4 \mathrm{~mm}$ in size in ureter (on X-ray KUB)] undergoing TUL with spinal anaesthesia. Exclusion criteria was based upon patients with urinary tract infections, urinary bladder cancer, having renal stones in kidney or ureter, previously diagnosed with acute renal colic, previously using non steroid anti-inflammatory drugs (NSAIDs), underwent repeated TUL, previously using corticosteroids, opioids, and patients diagnosed with anatomical or functional renal disorders. Acute renal colic patients were divided into two main groups with $1: 1$ randomization (using random number table). In Group-A, patients underwent complete emptying urinary bladder through Foleys catheter. Bladder was irrigated with aminophylline $(250 \mathrm{mg} / 10 \mathrm{~mL}$ mixed with $150 \mathrm{ml}$ normal saline) using ureteroscope. After this process, researcher waited for 5 minutes before starting procedure of TUL. However, group B (placebo) patients were underwent normal saline administration only. Both groups were underwent spinal anesthesia for TUL procedure by researcher. Irrigation of fluids leads to better vision and washing stone fragments. Outcomes were measured in terms of duration of TUL and complete removal of stone. Data was analyzed using SPSS version 24. Central tendency measures (mean and standard deviation) was measured for Body mass index (BMI), age, duration of procedure, duration of colic pain. Categorical variables like gender and complete stone removal were analyzed in terms of frequency and percentages. Effect modifiers were controlled through stratification. Post stratification chisquare and independent sample t-test was applied for comparing outcomes. p-value $\leq 0.05$, was considered (statistically) significant.

\section{RESULTS:}

Total 90 cases were included in study. There were $49(54.4 \%)$ males and $41(45.6 \%)$ female. Mean age of patients was $47.56 \pm 18.1 S D$. Mean BMI 28.48 \pm 4.26 SD. Mean operative time was 44.30 minutes $\pm 8.2 S D$. Mean duration of pain was 8.5 minutes $\pm 2.1 S D$. Complete stone removal was seen in $72(80 \%)$ patients and incomplete removal was observed in $18(20 \%)$ patients.

Mean operative time was found to be significantly lower in group-A (aminophylline group) as compared to group-B (placebo group) (39.96 $6.9 \mathrm{SD}, 48.71 \pm 6.9 \mathrm{SD}, \mathrm{p}=0.000$ respectively) as shown in (table-I).

Group-A patients with age $<45$ years had lower operative time $(39.71 \pm 8.08)$ as compared to group- $B(48.18 \pm 7.35)(p=0.003)$. Patients in aminophylline group had significantly lower mean operative time as compared to placebo with age $\geq 45$ years $(p=0.000)$. Patients in group-A with BMI $<28 \mathrm{~kg} / \mathrm{m} 2(p=0.000)$ and $\geq 28 \mathrm{~kg} / \mathrm{m} 2(p=0.000)$ had significantly lower mean operative time as compared to group- $B$. Male and females in group-A had lower mean operative time as compared to male and female in group-B $(p=0.000$ and $p=0.003$ respectively). Patients with duration of diagnosis $\leq 8$ days in group-A had significantly lower mean operative time as compared to group-B $(p=0.000)$. Similarly patients with duration of diagnosis $>8$ days in group- $A$ had mean operative time lower than group- $B(p=$ 0.0001 ) as shown in (Table-II).

Group-A (Aminophylline) patients showed significantly high stone removal frequency as compared to Group-B (44.4\% vs $35.6 \%$, $\mathrm{p}=0.03$ ) as shown in (Table-III). However, complete stone removal had insignificant association with age $(p=0.132)$, gender $(p=0.871)$, BMI $(p=0.342)$ and duration of diagnosis $(p=0.654)$ in both interventional groups. 
Table-I: Comparison of operative time in interventional and placebo group.

\begin{tabular}{|c|c|c|c|}
\hline Study Group & $\begin{array}{c}\mathbf{N} \\
(\mathbf{N}=90)\end{array}$ & $\begin{array}{c}\text { Operative time } \\
\text { Mean } \pm \mathbf{S D}\end{array}$ & p-value \\
\hline $\begin{array}{c}\text { Group A } \\
\text { (Aminophylline Group) }\end{array}$ & 45 & $39.96 \pm 6.99$ & 0.000 \\
\hline $\begin{array}{c}\text { Group B } \\
\text { (placebo group) }\end{array}$ & 45 & $48.71 \pm 6.95$ & \\
\hline
\end{tabular}

Table-II: Stratification of mean operative time in both groups with respect to age, BMI, gender and duration of diagnosis.

\begin{tabular}{|c|c|c|c|c|}
\hline Age & Groups & $\mathbf{N}$ & Operative Time & p-value \\
\hline \multirow{2}{*}{$<45$ years } & Group A & 18 & $39.71 \pm 8.08 \mathrm{SD}$ & \multirow[t]{2}{*}{0.003} \\
\hline & Group B & 17 & $48.18 \pm 7.35 S D$ & \\
\hline \multirow{2}{*}{$=45$ years } & Group A & 27 & $40.11 \pm 6.32$ & \multirow[t]{2}{*}{0.000} \\
\hline & Group B & 28 & $49.04 \pm 6.82$ & \\
\hline \multicolumn{5}{|l|}{ BMI } \\
\hline \multirow[t]{2}{*}{$<28$} & Group A & 19 & $33.74 \pm 3.23$ & \multirow{2}{*}{0.000} \\
\hline & Group B & 24 & $45.17 \pm 4.87$ & \\
\hline \multirow[t]{2}{*}{$=28$} & Group A & 26 & $44.50 \pm 5.26$ & \multirow{2}{*}{0.000} \\
\hline & Group B & 21 & $52.76 \pm 6.83$ & \\
\hline \multicolumn{5}{|l|}{ Gender } \\
\hline \multirow[t]{2}{*}{ Male } & Group A & 25 & $40.28 \pm 6.37$ & \multirow[t]{2}{*}{0.000} \\
\hline & Group B & 24 & $50.38 \pm 6.86$ & \\
\hline Female & Group A & 20 & $39.55 \pm 7.87$ & \multirow[t]{2}{*}{0.003} \\
\hline & Group B & 21 & $46.81 \pm 6.73$ & \\
\hline \multicolumn{5}{|c|}{ Duration of Diagnosis } \\
\hline$=8$ days & Group A & 23 & $38.87 \pm 7.02$ & \multirow[t]{2}{*}{0.01} \\
\hline & Group B & 23 & $48.65 \pm 6.37$ & \\
\hline \multirow{2}{*}{$>8$ days } & Group A & 22 & $41.09 \pm 6.95$ & \multirow{2}{*}{0.0001} \\
\hline & Group B & 22 & $48.77 \pm 7.67$ & \\
\hline
\end{tabular}

Table-III: Comparison of stone removal in interventional and placebo group.

\begin{tabular}{|c|c|c|c|c|}
\hline \multirow{2}{*}{$\begin{array}{c}\text { Stone } \\
\text { Removal }\end{array}$} & \multicolumn{2}{|c|}{ Interventional Groups } & \multirow{2}{*}{ Total } & \multirow{2}{*}{ p-value } \\
\cline { 2 - 4 } & Group-A & $\begin{array}{c}\text { (Aminophylline)Group-B } \\
\text { (Placebo) }\end{array}$ & \\
\hline No & $5(5.6 \%)$ & $13(14.4 \%)$ & $18(20 \%)$ & \multirow{2}{*}{0.03} \\
\hline Yes & $40(44.4 \%)$ & $32(35.6 \%)$ & $72(80 \%)$ & \\
\hline Total & $45(50 \%)$ & $45(50 \%)$ & $90(100 \%)$ & \\
\hline
\end{tabular}

\section{DISCUSSION:}

In present study, total 90 patients of acute renal colic were included (45 patients in each group). A significantly high stone removal distribution was observed in aminophylline group as compared to placebo $(p=0.03)$.
Barzegarnezhad et al, reported that local administration of aminophylline during TUL leads to $95 \%$ success rate in interventional group as compared to placebo $(72 \%)^{[9]}$. Mulay et al, reported that aminophylline group did not show any side effects similar to our study ${ }^{[11]}$. Rodger et al. reported that aminophylline is 
associated with significant antispasm effects on ureter influencing ureteral movement, retrograde access to ureter and helps in cleanup stone ${ }^{[12]}$.

In present study, aminophylline group underwent least mean operative time during TUL as compared to placebo $(p=0.000)$. However, Nickels et al. reported high success rate of aminophylline group in terms of low short duration of operation (TUL) $(4.2 \pm 2.61 \&$ $8.4 \pm 2.9)^{[13]}$. Ames et al. reported that aminophylline local administration is very effective in patients with uretero-pelvic spasm and ureteral/infundibular spasm leading towards un differentiation of stone related strictures ${ }^{[14]}$. Aminophylline is also effective in treatment of calycealstaghorn stones with significant access to stone related strictures ${ }^{[15]}$. In present study aminophylline act as a nonselective inhibitor and antagonist. However, Green et al. reported that upper urinary tract smooth muscles could be relaxed using aminophylline, phophosdiesterase inhibitors and methylxanthine. They reported an application of $0.5 \%$ aminophylline (topically) in $3 \mathrm{~mL}$ a mong ureteropelvic and ureteral/infundibular spasm patients ${ }^{[16]}$. Moreover, ureteral scaring leading towards secondary spasm could be resolved with methylxanthine-induced smooth muscle relaxation ${ }^{[17]}$.

In present study mean operative time was significantly lower in group A (interventional group) among females, age $<45$ years, $\mathrm{BMI}<28 \mathrm{~kg} / \mathrm{m} 2$ and duration of diagnosis $\leq 8$ days as compared to placebo. Another similar study reported that aminophylline is found to be safe and effective irrespective of age and gender ${ }^{[18]}$. While mahemuti et al, reported that duration of diagnosis had significant impact on efficacy of aminophylline. Shorter duration had positive association with high aminophylline efficacy ${ }^{[19]}$. Lin et al, reported that efficacy of aminophylline is more frequently high among males as compared to females $(p=0.000)^{[20]}$.

\section{CONCLUSION:}

Aminophylline is an effective and safe drug in terms of lower operative time and complete stone removal among acute renal colic patients undergoing transureteral lithotripsy. However, early diagnosis of acute renal colic leads to better disease prognosis and effective management.

\section{ACKNOWLEDGMENT: None}

CONFLICT OF INTEREST: All authors

disclose no conflict of interest.

\section{GRANT SUPPORT \& FINANCIAL DISCLOSURES: None.}

\section{REFERENCES:}

1. Ganti S, Sohil P. Renal Colic: A Red Herring for Mucocele of the Appendiceal Stump. Case Reports in Emergency Medicine. $2018 ; 3(2): 2502183$ D O I : $10.1155 / 2018 / 2502183$

2. Kutilek S, Plasilova I, Chrobok V. Two Different Causes of Paediatric Hypercalcaemia. Sultan Qaboos University Medical Journal. 2018;18(3):389-e392. DOI:10.18295/squmj.2018

3. Nadav G, Eyal K, Noam T, Yeruham K. Evaluation of the clinical significance of sonographicperinephric fluid in patients with renal colic. American Journal of Emergency Medicine. 2019;37(10):18231828.

4. Gandhi A, Hashemzehi T, Batura D. The management of acute renal colic. British Journal of Hospital Medicine (London). 2019;80(1):C2-C6. DOI: 10.12968/hmed. 2019.80.1.C2.

5. Kheyfets VK. Features of urolithiasis in patients of advanced and senile age. Advances in Gerontology. 2018;31(3):368373. PMID: 30584876.

6. D'Costa MR, Pais VM, Rule AD. Leave no stone unturned: defining recurrence in kidney stone formers. Current Opinion in Nephrology and Hypertension. $2019 ; 28(2): 148-153$. DOI:101097/MNH.0000000000000478 PMID: 30531469.

7. Raja AS, Pourjabbar S, Ip IK, Baugh CW, Sodickson AD, O'Leary $M$, et al. Impact of a Health Information Technology-Enabled Appropriate Use Criterion on Utilization of Emergency Department CT for Renal Colic. American Journal of Roentgenology. 
2019;212(1):142-145. DOI: $10.2214 /$ AJR.18.19966.

8. Masic D, Liang E, Long C, Sterk EJ, Barbas $B$, Rech MA. Intravenous Lidocaine for Acute Pain: A Systematic Review. Pharmacotherapy. 2018;38(12):12501259. DOI: 10. 1002/phor. 2189. E Pub 2018 Nov. 9.

9. Barzegarnezhad A, Firouzian A, Emadi AS, Mousanejad N, Bakhshali R. The effects of local administration of aminophylline on transureteral lithotripsy. Advances in Urology.2012;3(2):727843. DOI: 10 . $1155 / 2012 / 727843$.

10. Djaladat H, Tajik P, Fard SA, Alehashemi S. The effect of aminophylline on renal colic: a randomized double blind controlled trial. Southern Medical Journal. 2007;100 (11):1081-1084.

11. Mulay SR, Shi C, Ma X, Anders HJ. Novel Insights into Crystal-Induced Kidney Injury. Kidney Diseases (Basel). 2018;4(2):49-57. DOI: 10.1159/ 000487671.

12. Rodger F, Roditi G, Aboumarzouk OM. Diagnostic Accuracy of Low and Ultra-Low Dose CT for Identification of Urinary Tract Stones: A Systematic Review. Urology. International. 2018;100(4):375-385. DOI: $10.1159 / 000488062$.

13. Nickels TJ, Schwartz AD, Blevins DE, Drummond JT, Reed GW, Wilson DF. Effect of theophylline and aminophylline on transmitter release at the mammalian neuromuscular junction is not mediated by CAMP. Clinical and Experimental Pharmacology and Physiology. 2006;33(56) :465-470. DOi:10.1111/j.14401681.2006.04388.x.

14. Ames CD, Weld KJ, Dryer ST, Hruby G, Minor SD, Yan Y, et al. Pharmacologic manipulation of the porcine ureter: acute impact of topical drugs on ureteral diameter and peristaltic activity. Journal of Endourology. 2006;20(11):943-948. DOI: $10.1089 /$ end.2006.20.943.

15. Danuser $H$, Weiss $R$, Abel $D$, Walter $B$, Scholtysik G, Mettler D, et al. Systemic and topical drug administration in the pig ureter: effect of phosphodiesterase inhibitors $a 1, \beta$ and $\beta 2$-adrenergic receptor agonists and antagonists on the frequency and amplitude of ureteral contractions. Journal of Urology. 2001;166(2):714-720. DOI:10.1016/S0022-5347(05)66049-1.

16. Green DF, Glickman MG, Weiss RM. Preliminary results with aminophylline as smooth-muscle relaxant in percutaneous renal surgery. Journal of Endourology. 1987;1(3):243-247. DOI:10.1089/ end.1987.1.243.

17. Stower MJ, Clark AG, Wright JW, Hardcastle $J D$. The effect of various drugs on canine ureteric peristalsis. Urological Research. 1986;14(1):41-44. DOI:10.1007/ BF00255532.

18. Bloch R, Decker N, Kostakopoulos A. Effects of theophylline and isoproterenol on the activity on the isolated guinea pig ureter. Urologia Internationalis. 1984;39(5): 308-311. DOI:10.1159/000280999.

19. Mahemuti G, Zhang H, Li J, Tieliwaerdi N, Ren L. Efficacy and side effects of intravenous theophylline in acute asthma: a systematic review and meta-analysis. Drug Design Development and Therapy. 2018; 12(2): 99-120. DOI: 10.2147/ DDDT.S156509 PMID: 29391776.

20. Lin LF, Cheng CY, Hou CH, Ku CH, Tseng NC, Shen DH. Experience of low-dose aminophylline use to relieve minor adverse effects of dipyridamole in patients undergoing stress myocardial perfusion imaging. Journal of Nuclear Cardiology. 2014;21(3):563-569. DOI:10.1007/ s12350-014-9883-7

\section{Authors' Contribution:}

Hasham Khan: Data collection and designing. Ghulam Mustafa: Conceptualizing study and literature search.

Saqib Butt: Data analysis and interpretation. Noor-Un-Nisa: Write ups and proof reading. Ehsan-Ul-Haque: Critical appraisal.

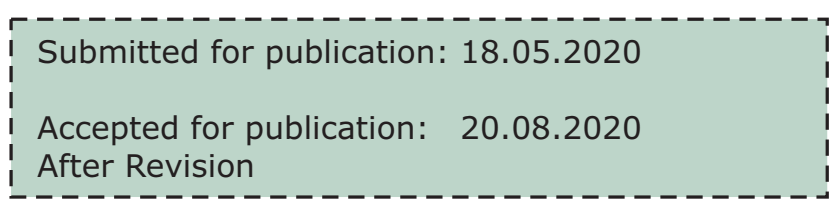

